\title{
A new taxonomy for describing and defining adherence to medications
}

\author{
Bernard Vrijens, ${ }^{1,2}$ Sabina De Geest, ${ }^{3,4}$ Dyfrig A. Hughes, ${ }^{5}$ \\ Kardas Przemyslaw, ${ }^{6}$ Jenny Demonceau, ${ }^{1}$ Todd Ruppar, ${ }^{3,7}$ \\ Fabienne Dobbels, ${ }^{3}$ Emily Fargher, ${ }^{5}$ Valerie Morrison, ${ }^{5}$ Pawel Lewek, ${ }^{6}$ \\ Michal Matyjaszczyk, ${ }^{6}$ Comfort Mshelia, ${ }^{8}$ Wendy Clyne, ${ }^{8}$ \\ Jeffrey K. Aronson ${ }^{9} \&$ J. Urquhart, ${ }^{1,10}$ for the ABC Project Team \\ ${ }^{1}$ AARDEX Group Ltd, Sion, Switzerland, ${ }^{2}$ Department of Biostatistics and Medical Informatics, University \\ of Liège, Liège, Belgium, ${ }^{3}$ Center for Health Services and Nursing Research, Katholieke Universiteit \\ Leuven, Leuven, Belgium, ${ }^{4}$ Institute of Nursing Science, Faculty of Medicine, University of Basel, Basel, \\ Switzerland, ${ }^{5}$ Bangor University, Bangor, Wales, UK, ${ }^{6}$ Medical University of Lodz, Lodz, Poland, ${ }^{7}$ Sinclair \\ School of Nursing, University of Missouri, Columbia, Missouri, USA, ${ }^{8}$ NPC Plus, Keele University, Keele, \\ UK, ${ }^{9}$ Department of Primary Health Care, University of Oxford, Oxford, UK and ${ }^{10}$ Department of \\ Bioengineering \& Therapeutic Sciences, UCSF, San Francisco, California, USA
}

Correspondence

Dr Bernard Vrijens, AARDEX Group Ltd,

Sion, Switzerland.

Tel.: +3243748635

Fax: +4127324788

E-mail: bernard.vrijens@aardexgroup.com

Keywords

concordance, medication adherence,

patient compliance, persistence,

taxonomy, terminology

Received

4 July 2011

Accepted

17 December 2011

Accepted Article

Published Online

16 January 2012

Interest in patient adherence has increased in recent years, with a growing literature that shows the pervasiveness of poor adherence to appropriately prescribed medications. However, four decades of adherence research has not resulted in uniformity in the terminology used to describe deviations from prescribed therapies. The aim of this review was to propose a new taxonomy, in which adherence to medications is conceptualized, based on behavioural and pharmacological science, and which will support quantifiable parameters. A systematic literature review was performed using MEDLINE, EMBASE, CINAHL, the Cochrane Library and PsycINFO from database inception to 1 April 2009. The objective was to identify the different conceptual approaches to adherence research. Definitions were analyzed according to time and methodological perspectives. A taxonomic approach was subsequently derived, evaluated and discussed with international experts. More than 10 different terms describing medication-taking behaviour were identified through the literature review, often with differing meanings. The conceptual foundation for a new, transparent taxonomy relies on three elements, which make a clear distinction between processes that describe actions through established routines ('Adherence to medications','Management of adherence') and the discipline that studies those processes ('Adherence-related sciences'). 'Adherence to medications' is the process by which patients take their medication as prescribed, further divided into three quantifiable phases:'Initiation,' Implementation' and 'Discontinuation'. In response to the proliferation of ambiguous or unquantifiable terms in the literature on medication adherence, this research has resulted in a new conceptual foundation for a transparent taxonomy. The terms and definitions are focused on promoting consistency and quantification in terminology and methods to aid in the conduct, analysis and interpretation of scientific studies of medication adherence.

\section{Introduction}

Sub-optimal adherence to prescribed medicines is frequently the principal obstacle to successful pharmacotherapy in ambulatory patients, especially when it is unrecognized clinically, as often occurs. It is highly prevalent, associated with increased morbidity and mortality, costly to manage, and until recently a very much neglected aspect of therapeutics [1-3].

However, in the past decade there has been substantial growth in adherence research, partly owing to increasing awareness of the size and scope of the problem, partly because of the pervasiveness of non-adherence across all therapeutic fields and partly because of its potentially large contribution to the overall variance in drug responses. Many patients do not adhere to effective treatments for the preservation of life [4,5], quality of life [6-8], organs [9] or sight $[10,11]$, with direct clinical $[12,13]$ and economic consequences [14, 15].

Adherence research has also been spurred by improved methods for compiling dosing histories in ambulatory patients, recognition of the importance of 
adherence to treatment outcomes in HIV-AIDS, increasing sizes of study populations, and lengthening periods of observation. However, this growth has been piecemeal, with research contributions coming from a variety of perspectives or academic disciplines. A predictable consequence has been an unsatisfactory taxonomic structure, leading to conceptual confusion [16-19].

Currently a number of terms, e.g. 'compliance,' 'adherence', 'persistence', and 'concordance', are used to define different aspects of the act of seeking medical attention, acquiring prescriptions and taking medicines appropriately [20-37]. These terms are often used interchangeably, but they impose different views about the relationship between the patient and the health care professional [38-40]. 'Compliance', for instance, has been viewed by many as having the negative connotation that patients are subservient to prescribers [41-45]. The term 'concordance', introduced originally to describe the patient-prescriber relationship, is sometimes incorrectly used as a synonym for 'compliance' [46-57]. Most terms used currently do not have a clear or direct translation into different European languages [58]. These matters lead to confusion and misunderstanding, and impede comparisons of results of scientific research and implementation in practice $[59,60]$.

In this research we have searched the literature systematically, in order to identify the terms that have been used to describe medication-taking behaviour, and have outlined the taxonomic evolution of the field. As a result we have proposed a new taxonomy for medication taking behaviour that will support relevant measurements. This research was performed within the $A B C$ (Ascertaining Barriers to Compliance) project, which is an international collaboration of European research groups in the field of adherence to medications funded by the European Commission, Seventh Framework Programme.

\section{Methods}

The first step consisted of a systematic literature review performed between January and June 2009. The objective was to assess the terms and definitions that are commonly used to describe adherence to medicines. We searched MEDLINE, EMBASE, CINAHL, the Cochrane Library and PsycINFO from database inception to 1 April 2009 for all papers addressing the taxonomy/terminology used to describe deviations from prescribed drug treatment in ambulatory patients. The main search terms used were 'Patient compliance' and 'Medication adherence'. Because of the problem with translations, the searches were limited to papers in the English language. Detailed search strategies specific to the different databases are provided in Appendix 1.

Data extraction was undertaken by five independent reviewers (JD, FD, EF, CM, PL) using a structured data collection sheet to gather data on (i) publication type, (ii) year of publication, (iii) authors' preferred terms for describing deviations from prescribed treatment, (iv) authors' proposed definitions and $(v)$ references cited in the paper. No additional information was sought from the authors.

A descriptive synthesis of the extracted data was performed and the historical development of the field was analyzed. Based on the different conceptual approaches identified in the literature review, we derived an initial new taxonomic approach, which was first discussed internally within the $A B C$ project team in June 2009 in Aberdeen, UK. The taxonomic approach was subsequently re-evaluated in light of the identified papers and refined in June-August 2009.

A European consensus meeting, attended by 80 participants from 13 different countries, was organized jointly with the European Society for Patient Adherence, Compliance and Persistence (ESPACOMP) in Bangor, Wales, UK on 10-11 September, 2009. During the meeting the draft consensus document was presented and extensively discussed. To broaden this discussion, an interactive wiki webplatform was opened during the last quarter of 2009.

In December 2009, a first report on the new taxonomy was submitted to the EU Commission. In January 2010, an $A B C$ internal consensus meeting was held in Sion, Switzerland. During that meeting, the strengths and weaknesses of the draft taxonomy were identified. From January 2010 until June 2010, the draft taxonomy was presented at different meetings and specific comments from experts were collected.

A final $A B C$ internal consensus meeting took place in Leuven, Belgium in June 2010 for final approval of the taxonomy/terminology, which was subsequently presented at the 2010 ESPACOMP meeting held on 17-18 September in Lodz, Poland.

\section{Results}

\section{Results from the literature review}

Study selection Figure 1 depicts the study selection process. Initial searching identified 3121 papers. Two thousand nine hundred and seventy-five original articles were excluded according to pre-defined exclusion criteria listed in Figure 1, resulting in 146 papers to review. The publication types were literature reviews $(n=55)$, editorials/ commentaries/letters/discussions $(n=34)$, theoretical papers/concept analyses $(n=21)$, research papers $(n=17)$, books $(n=9)$, statistical papers $(n=4)$, meeting reports $(n=$ $3)$, practice guidelines $(n=2)$ and an expert report $(n=1)$.

Terms identified Figure 2 illustrates the many different terms describing deviations from prescribed treatment that have been introduced in the literature throughout the years. The data shown in this figure are incomplete for the year 2009, as papers were included up to 1 April 2009. Since the pioneering research in this field, changes 


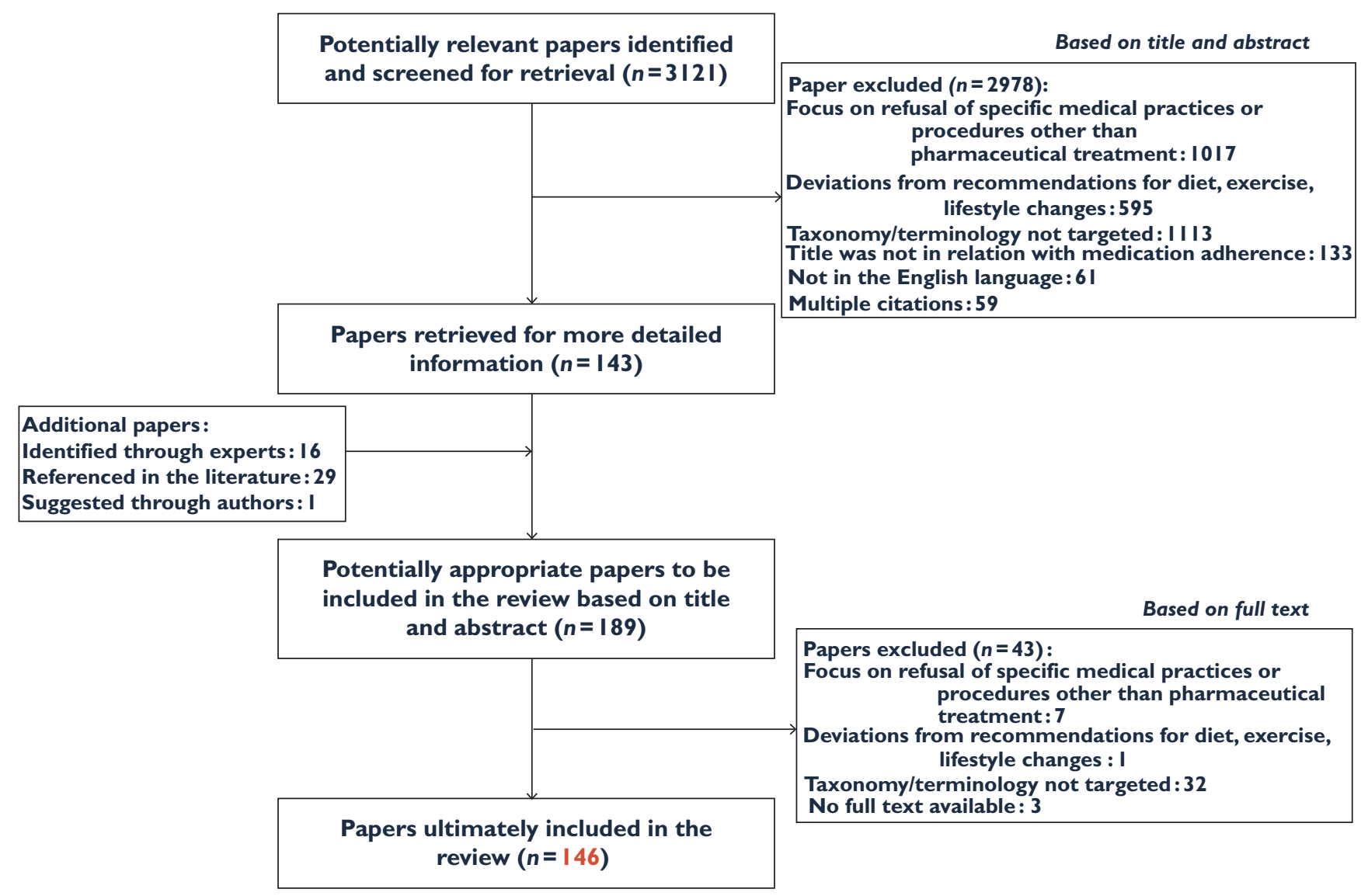

\section{Figure 1}

Flow diagram of the paper selection process

have occurred in prevailing philosophical paradigms and related concepts [61-63] as depicted in Figure 3.

Hippocrates (400 BC) was the first to note that some patients do not take their prescribed medicines, and that many later complained because the treatment did not help. In 1882, for the first time in modern medicine, Robert Koch stipulated that noncompliant patients with tuberculosis were 'vicious consumptives, careless and/or irresponsible' [61].

Beginning in the 1970s, groundwork on patient compliance was initiated at McMaster University Medical Centre, resulting in two workshops/symposia and a seminal book entitled 'Compliance with Therapeutic Regimens' by Sackett \& Haynes [64]. This initial research was triggered by the potential clinical consequences of patient non-adherence and their impact on the results of clinical trials. It was driven by a biomedical (pharmacometric) perspective that was concerned with pragmatic methods to answer empirical questions about ambulatory patients' deviations from prescribed medication, and focused on the quantitative evaluation of the degree of correspondence between the prescription and the ensuing implementation of the prescribed dosing regimen [65].The term
'Patient compliance' was introduced in 1975 as an official Medical Subject Heading (MeSH) in the US National Library of Medicine $[66,67]$. The term 'pharmionics', introduced in 1987 , is defined as the discipline that studies how ambulatory patients use and misuse prescription drugs [68-70].

During early research, the role of patients' views on these matters was neglected, but a later body of research addressed how prescriptions are generated, the patient's perspective in treatment choices and treatment management in daily life [71]. In the meantime, 'compliance' has been increasingly replaced by 'adherence' $[3,72,73]$, as the latter term has been thought to evoke more the idea of cooperation between prescriber and patient, and less the connotation of the patient's passive obedience to the physician's instructions [74-78]. The shift from 'compliance' to 'adherence' reflects a fundamental change in understanding relationships between patients and practitioners [79-81].

It was in the light of this shift that the term 'concordance' was proposed $[82,83]$.'Concordance' was first introduced by a joint working group assembled by the Royal Pharmaceutical Society of Great Britain in 1995. The 'concordance' construct recognized the need for patients and health care 


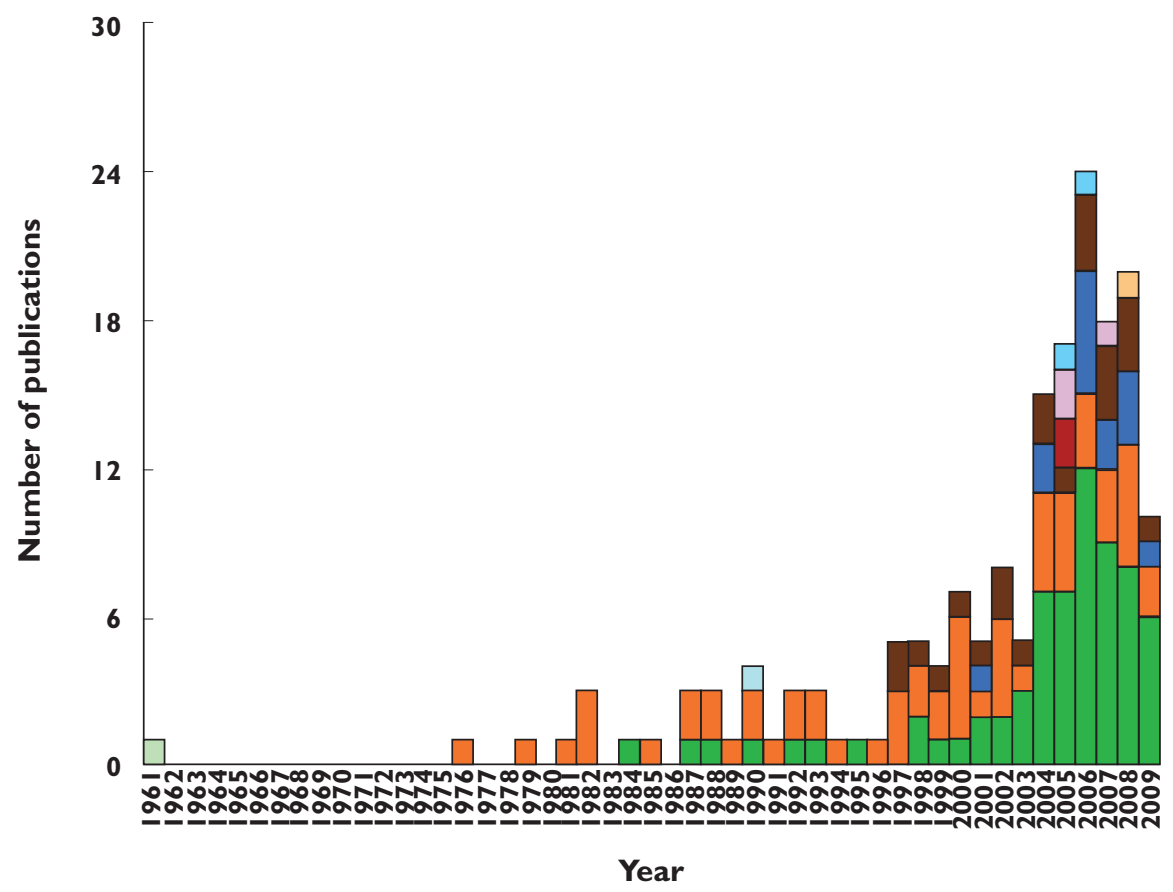

\section{Figure 2}

Frequency histogram presenting the evolution over time of the main terms used among the 146 papers to describe deviations from prescribed treatments. Adherence ( $\square$ ); Compliance ( $\square$ ); Persistence ( $\square$ ); Concordance ( $\square$ ); Pharmionics ( $\square$ ); Therapeutic Alliance ( $\square$ ); Persistency ( $\square$ ); Patient irregularity ( $\square$ ); Pharmacoadherence ( $\square)$; Other $(\square)$

providers to cooperate in the definition of a mutually agreed treatment programme, acknowledging that patients and providers may have differing views [83-91].

In 1997 the American Heart Association issued a statement [92] in which adherence was defined as a behavioural process, strongly influenced by the environment in which the patient lives, including health care practices and systems $[93,94]$. This statement contained the assumption that satisfactory adherence depends on patients' having the knowledge, motivation, skills and resources required to follow the recommendations of a health care professional.

In 2005, an important step was the recognition of both the intentional and unintentional aspects of nonadherence to medications [95-99]. Both facets need to be addressed simultaneously to solve this important health care problem. The term 'medication adherence' was introduced as a MeSH term in 2009.

'Compliance' and 'adherence' share the property of being quantifiable parameters, which detail when doses are taken and how much drug each dose provides. 'Concordance', 'cooperation', 'agreement' and 'therapeutic alliance' imply a certain 'meeting of the minds/perspectives' of carers/caregivers and patients [100-105] regarding a treatment plan suitable for a course of pharmacotherapy, during which the patients and/or carers/caregivers bear the responsibility for correct administration of the medicine(s) [106-108].The definition of 'correct' is ambiguous in the reviewed papers, because there are certain scientific aspects of when and how much of certain drugs should be taken that are not negotiable if the prescribed medicine is to work satisfactorily, e.g. the low dose combined oral contraceptives, the effectiveness and safety of which depend on specific doses and strict punctuality in the taking of successive doses.

Cited references The most commonly cited text for the definition of patient compliance is a 1976 paper by Sackett \& Haynes [64]. As illustrated in Table 1, several attempts have been taken to adapt the original definition of patient compliance in order to emphasize its psychological, behavioural and ecological aspects. For example, the WHO definition of adherence addresses the need for patients to be involved in treatment decisions. However, this change illustrates the potential confusion triggered by a conceptual change, i.e. the implied need for prior agreement between prescriber and patient regarding the treatment plan, without regard to the measurement problem it generates. That problem arises because of the need for (i) a method to measure the coincidence of the patient's behaviour and the provider's recommendation, (ii) a method for measuring agreement between the patient and care-provider, plus (iii) means to avoid the resulting methodological impasse by finding ways to integrate these two dimensionally different measurements. 


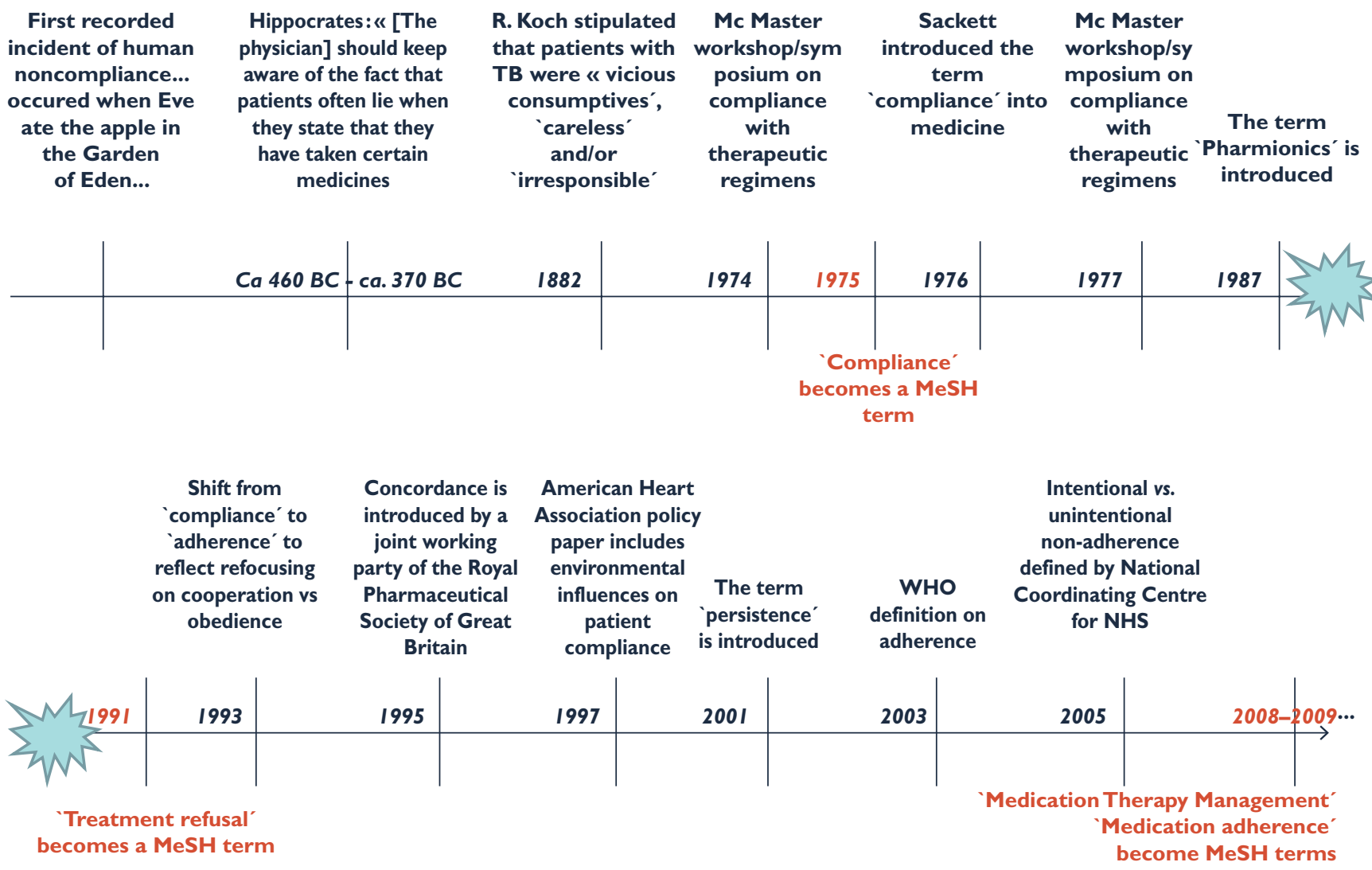

\section{Figure 3}

Time-line of changes in terminology for deviations from prescribed dosing regimens

\section{Table 1}

Illustration of changes and adaptations of the original definition of patient compliance over the years

\section{Definition}

Compliance is the extent to which the patient's behaviour (in terms of taking medications, following diets or executing other lifestyle changes) coincides with the clinical prescription.

Compliance is the extent to which the patient's behaviour coincides with the clinical prescription, regardless of how the latter was generated.

Compliance is the extent to which a person's behaviour (in terms of taking medication: following diets, or executing other lifestyle changes) coincides with medical or health advice.

Compliance is the extent to which an individual chooses behaviours that coincide with a clinical prescription, the regimen must be consensual, that is, achieved through negotiations between the health professional and the patient.

Adherence is the degree to which a patient follows the instructions, proscriptions, and prescriptions of his or her doctor.

Adherence is the extent to which a person's behaviour - taking medication, following a diet, and/or executing lifestyle changes - corresponds with agreed recommendations from a health care provider.

Adherence is the extent to which a patient participates in a treatment regimen after he or she agrees to that regimen.
Authors - Year

Sackett \& Haynes (1976) [64]

Sackett \& Haynes (1976) [64]

Haynes et al. (1979) [143]

Dracup \& Meleis (1982) [144]

Meichenbaum \& Turk (1987) [145]

World Health Organization; (2003) [3]

Balkrishnan (2005) [146]
In summary, 'patient compliance' and 'medication adherence' have been the most widely-used terms, each serving as indexing terms in the Index Medicus of the US National Library of Medicine. However, the definitions of these terms are unsatisfactory $[109,110]$, as they are used interchangeably but inconsistently to define variation or uncertainties in the linkages between seeking medical attention, acquiring prescriptions [111], and deviating 
from the administration of medicines as prescribed [112-114].

Because of the breadth of the topic and the multiple behaviours that are subsumed under it, no single term (e.g. 'adherence') or definition meets all needs of the field [115128]. There is thus a clear need to create an agreed set of rules [129], within which future activities can fit, to provide concise and adequate definitions and an associated conceptual framework that could serve the needs of both clinical research and medical practice $[129,130]$.

\section{Results from the European Consensus Meeting} At the $13^{\text {th }}$ annual ESPACOMP meeting in September 2009 at Bangor University, Wales, UK, the ABC consortium coordinated the 'European consensus meeting on the taxonomy and terminology of patient compliance'. A proposal for a sound taxonomy/terminology in the field of patient adherence was introduced by $\mathrm{Dr}$ Bernard Vrijens (ABC work-package leader) who presented the research work that had been performed within the $A B C$ project and proposed a new taxonomy.

The meeting was attended by 80 participants from Australia, Belgium, Denmark, France, Germany, Italy, the Netherlands, Norway, Poland, Portugal, Switzerland, the United Kingdom and the United States.

Dr Jeffrey Aronson (University of Oxford, UK) chaired the session and supervised the interactive discussion with the participants. Dr Lars Osterberg (Stanford University School of Medicine, Stanford, California, USA) and Dr Robert Vander Stichele (University of Ghent, Belgium) participated in a panel discussion. Discussions were recorded. During the meeting, 40 attendees participated in the electronic voting on a consensus on taxonomy in the field of deviations from prescribed treatment.

Forty-six \% of the audience indicated that they had been involved in matters relating to adherence for 2-5 years, $57 \%$ were researchers and $25 \%$ were health care professionals. Forty-eight \% were from academia, 15\% from pharmaceutical companies and $8 \%$ from health services. Twenty-five \% were clinically qualified as medical doctors, $30 \%$ as pharmacists, and $5 \%$ as nurses.

Most (60\%) of the participants declared that the term 'Medication adherence' was their preferred term for describing patients' medicines taking behaviour vs. $25 \%$ who voted for the term 'Patient compliance'. When asked for the designation of a certain level of compliance ('What does it mean to you to read that a clinical study reported a compliance level of 90\%?'), the opinions were inconsistent. This finding suggests that some of the widely used terms have quite different meanings to researchers working within different scientific and medical fields. These differences are one of the reasons why it is important to forge a uniform taxonomy that supports quantitative, pharmacometrically sound assessment. However $95 \%$ of the audience did distinguish between how long a treatment is pursued from how well a dosing regimen is implemented.
Fifty-three $\%$ of the participants considered that the terms adherence and compliance might be used interchangeably but considered that the term 'concordance' has a distinctly different meaning from either 'adherence' or 'compliance'. A majority (61\%) of the voters preferred the term 'discontinuation' to describe patients' premature ending of prescribed therapy while $37 \%$ preferred the term 'non-persistence'. Participants were then asked whether they agreed with the proposed taxonomy previously presented by Dr Bernard Vrijens. A majority (77\%) agreed with the proposed taxonomy and $72 \%$ also agreed with the proposed terminology; $15 \%$ were not sure about the proposal. If a European consensus on terminology were to be produced, $49 \%$ of the participants said that they would use it irrespective of whether they agreed with the content and $46 \%$ said that they would use it sometimes.

To broaden this discussion to a larger public it was decided to use a wiki-type collaborative web-platform. An announcement of this website has been sent to the members of the ESPACOMP mailing list $(n=1321)$ to invite them to sign up on this platform and to share some of their thoughts and opinions on this important topic with the wider public who are interested in patient adherence. The revised taxonomy originally posted on the wiki webplatform was well attended with up to 125 visits/day but few comments were posted.

\section{A proposed taxonomy/terminology}

The new conceptual foundation for a transparent taxonomy relies on three elements, which make a clear distinction between processes that describe actions through established routines ('Adherence to medications,'Management of adherence') and the disciplines which study those processes ('Adherence-related sciences'). The proposed taxonomy is described below and the corresponding terms and definitions are summarized in Table 2.

Adherence to medications The first element is named adherence to medications, the process by which patients take their medications as prescribed. Adherence has three components: initiation, implementation, and discontinuation (see Figure 4). The process starts with initiation of the treatment, when the patient takes the first dose of a prescribed medication. The process continues with the implementation of the dosing regimen, defined as the extent to which a patient's actual dosing corresponds to the prescribed dosing regimen, from initiation until the last dose is taken. Discontinuation marks the end of therapy, when the next dose to be taken is omitted and no more doses are taken thereafter. Persistence is the length of time between initiation and the last dose, which immediately precedes discontinuation.

Non-adherence to medications can thus occur in the following situations or combinations thereof: late or non-initiation of the prescribed treatment, sub-optimal 


\section{Table 2}

Summary of the taxonomy and definitions

\begin{tabular}{|c|c|}
\hline Taxonomy & Definition \\
\hline Adherence to medications & $\begin{array}{l}\text { The process by which patients take their medications as prescribed, composed of initiation, implementation and discontinuation. } \\
\text { Initiation occurs when the patient takes the first dose of a prescribed medication. } \\
\text { Discontinuation occurs when the patient stops taking the prescribed medication, for whatever reason(s). } \\
\text { Implementation is the extent to which a patient's actual dosing corresponds to the prescribed dosing regimen, from initiation until the last } \\
\text { dose. } \\
\text { Persistence is the length of time between initiation and the last dose, which immediately precedes discontinuation. }\end{array}$ \\
\hline Management of adherence & $\begin{array}{l}\text { The process of monitoring and supporting patients' adherence to medications by health care systems, providers, patients, and their social } \\
\text { networks. }\end{array}$ \\
\hline Adherence-related sciences & $\begin{array}{l}\text { The disciplines that seek understanding of the causes or consequences of differences between prescribed (i.e. intended) and actual } \\
\text { exposures to medicines. }\end{array}$ \\
\hline
\end{tabular}

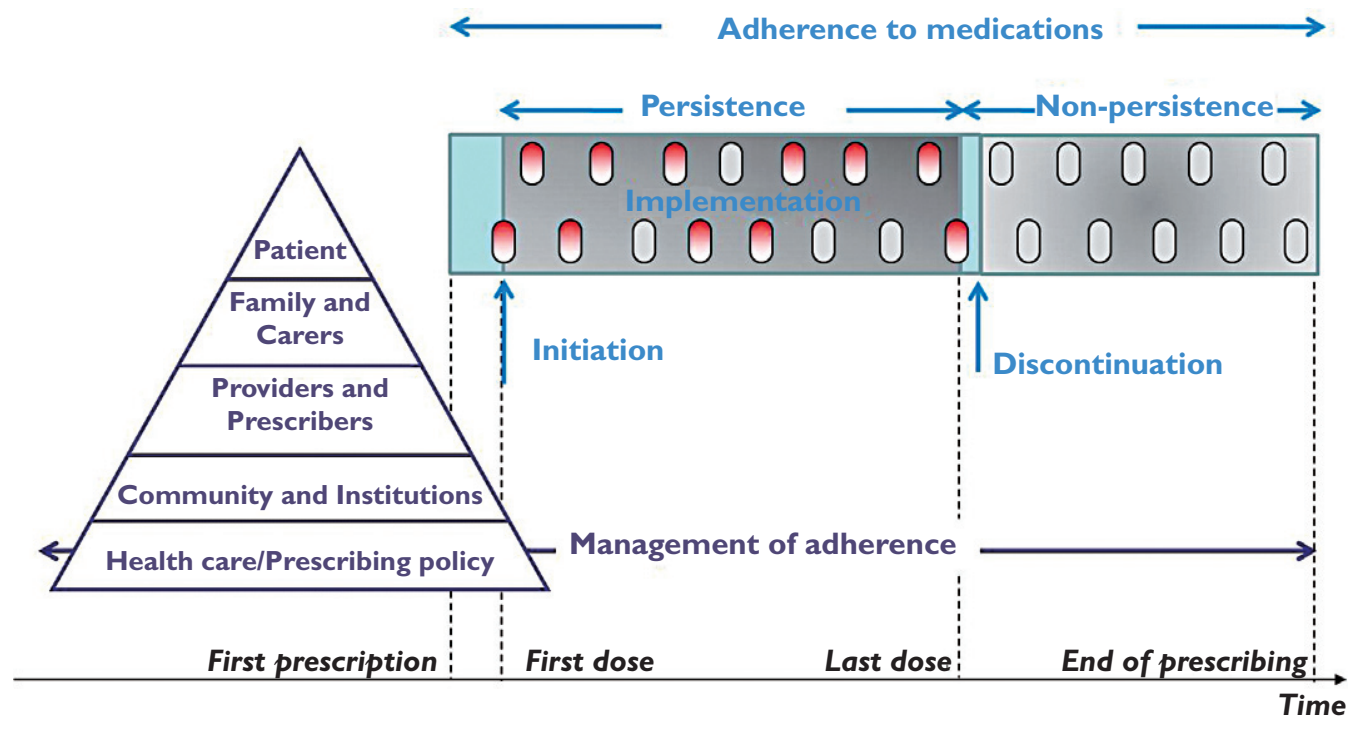

\section{Figure 4}

Illustration of the process of adherence to medication (light blue) and the process of management of adherence (dark blue)

implementation of the dosing regimen or early discontinuation of the treatment.

Management of adherence The second element of the taxonomy is named management of adherence, and is the process of monitoring and supporting patients' adherence to medications by health care systems, providers, patients, and their social networks. The objective of management of adherence is to achieve the best use by patients, of appropriately prescribed medicines, in order to maximize the potential for benefit and minimize the risk of harm.

Note that the Index Medicus includes the indexing term 'medication adherence', using 'medication' as a noun modifier. We prefer the term 'adherence to medication', but the two terms can be used interchangeably. Following the same argument, 'Adherence management' can be used as an alternative to 'Management of adherence'.
Adherence-related sciences The third element is named adherence-related sciences. This element includes the disciplines that seek understanding of the causes or consequences of differences between the prescribed (i.e. intended) and actual exposures to medicines. The complexity of this field, as well as its richness, results from the fact that it operates across the boundaries between many disciplines, including, but not limited to medicine, pharmacy, nursing, behavioural science, sociology, pharmacometrics, biostatistics and health economics.

\section{Quantification of adherence to medications}

An apt quantification of adherence to medications constitutes the basis for adherence-related sciences [131]. In turn, this quantification informs the process of managing adherence, the aim of which is to help patients to take appropriately prescribed drug dosing regimens. These regimens depend on scientifically sound regulatory 
labelling decisions, tempered by informed practices of prescribers, and guided by evolving principles of individualized prescribing as well as the support of patients in the daily management of their medication regimens. The ultimate goal is optimal pharmacotherapy and its implicit association with optimal clinical outcomes.

Pharmionics is an adherence-related science concerned with the quantitative assessment of the three measurable components of adherence to medications (initiation, implementation, and discontinuation), and their respective contributions toward the effects of medicines. Pharmionics is thus an adherence-related science that constitutes the link to the biomedical field of pharmacometrics as a natural input to pharmacokinetic and pharmacodynamic models for quantitative analysis and projection of the consequences of correct vs. incorrect dosing, and the effects of specific errors [70].

Initiation and discontinuation of treatment are inherently discontinuous actions, whereas implementation of the dosing regimen is continuous. This difference precludes a single, quantitatively useful parameter to cover all three. For example, the three patients illustrated in Figure 5 all took $75 \%$ of their prescribed twice daily doses over a period of 3 months. However, the electronically compiled drug dosing history data reveal major differences in the dynamics of the three components of adherence to medications over time, which can reveal different causes and/or consequences.

Initiation is often reported as the time from prescription until first dose is taken. It is thus a time-to-event variable with a well-defined time origin (prescription) and an end-point which is the first dose taken. We note that the end-point will not be observed for those patients who never take the first dose within the studied period; in that case the end-point is censored.

Persistence is the time from initiation until discontinuation. It is also a time-to-event variable with a well defined time origin (initiation) and an end-point which is the time of treatment discontinuation. The end-point will be censored if the end-point is not observed during the studied period.

Both variables are thus time-to-event data and should be analyzed and interpreted using standard survival analysis. Kaplan-Meier curves, median persistence or proportion of persistent patients at a well defined time point are the most frequent representations used. We note that in clinical studies, patients sign an informed consent document, and typically the first dose is administered on site. Therefore, it is often assumed that initiation is implicit for all included patients. In that case, persistence is defined as the time from inclusion until discontinuation.

The quantification of implementation requires the comparison of two time-series: the prescribed drug dosing regimen and the patient's drug dosing history. Its estimation can range from a single summary statistic to a more longitudinal comparison.

The most frequent summary statistics for quantifying, within a patient, the implementation of a dosing regimen, over a defined interval of time, are:

1 the proportion of prescribed drug taken;

2 the proportion of days with the correct number of doses taken;

3 the proportion of doses taken on time, in relation to a prescription-defined time interval between successive doses;

4 the distribution of inter-dose intervals;

5 the number of drug holidays;

6 the longest interval between two doses.

However, summary statistics that are estimated over an aggregate period of time have limitations, especially when one wants to depict trends in the implementation of the dosing regimen over time. It is also important to note that some sparse measures of adherence which provide only aggregate estimate over a defined period of time (e.g. counting returned tablets) do not allow one to identify precisely the discontinuation time. Thus, summary statistics based on sparse measurement methods often mix the different elements of adherence to medications and can be very confusing.

More longitudinal comparisons which make clear distinctions between initiation, implementation, and discontinuation have been proposed, as illustrated previously using a large database of electronically compiled drug dosing histories among patients with hypertension [132].

Operational definitions for the implementation of a dosing regimen should be drug- and disease-specific. Clinically relevant definitions need to be developed, indicating which deviation from the prescribed medication regimen is sufficient to influence adversely the regimen's intended effect [133-135]. Further discussions on operational definitions are beyond our scope and have to do with the intricacies of time series analyses. However, the proposed taxonomy forms the cornerstone for concise adherence measurement and facilitates a smooth transition from conceptual to operational definitions.

\section{Discussion}

Despite four decades of adherence research, there is still no uniformity in the terminology used to describe deviation from prescribed regimens. Through its historical development, this field of research has operated across areas bounded by biomedical, ecological and behavioral perspectives, the respective concepts of which are categorically dissimilar [136]. This dissimilarity has resulted in the generation of a number of concepts and terms 


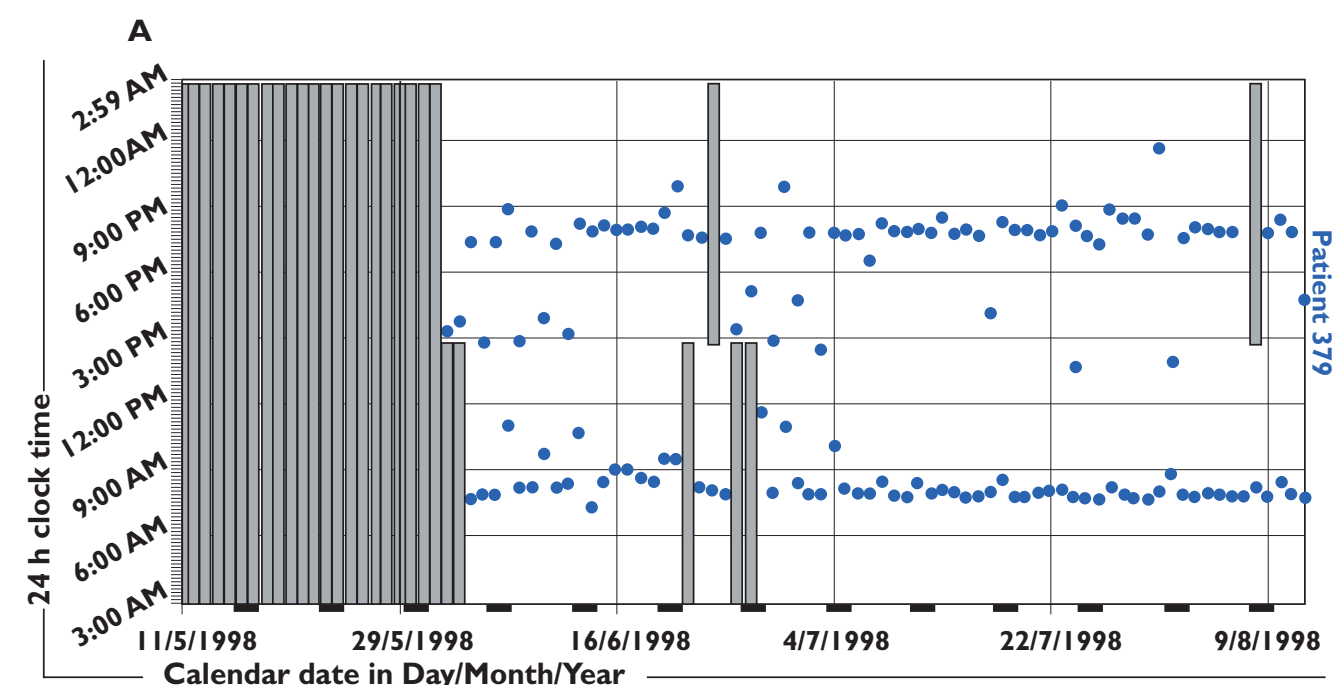

B

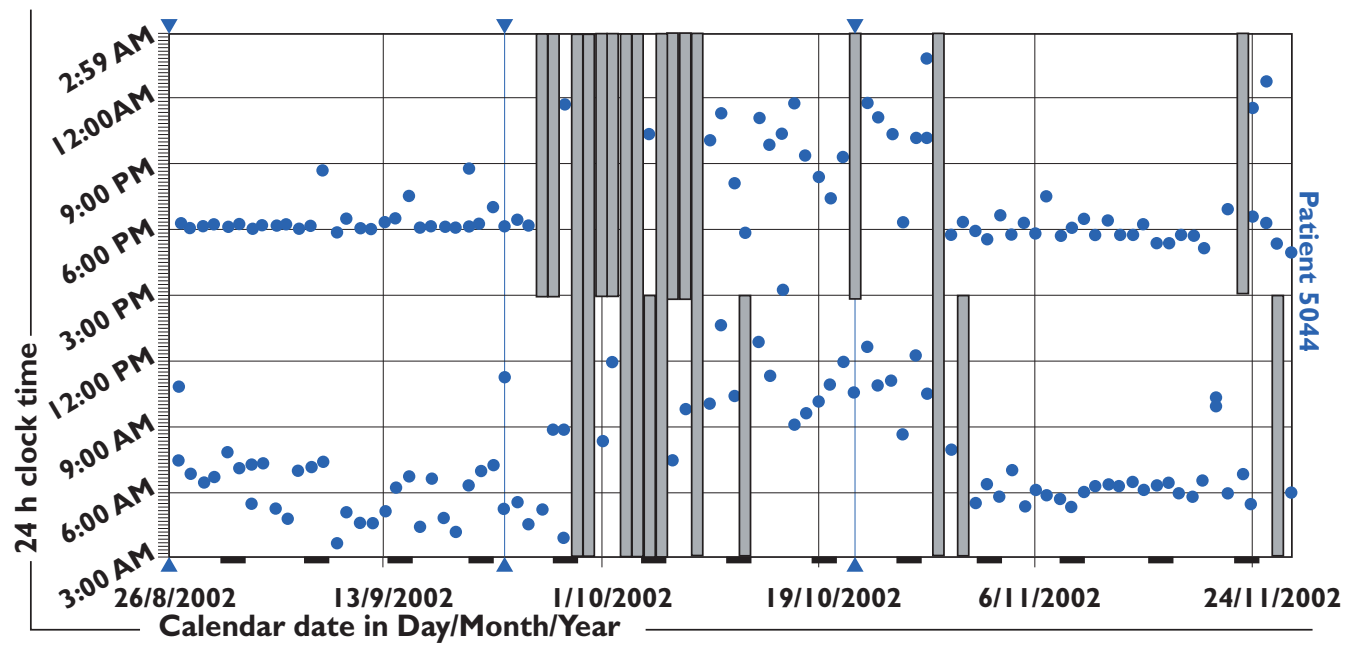

c

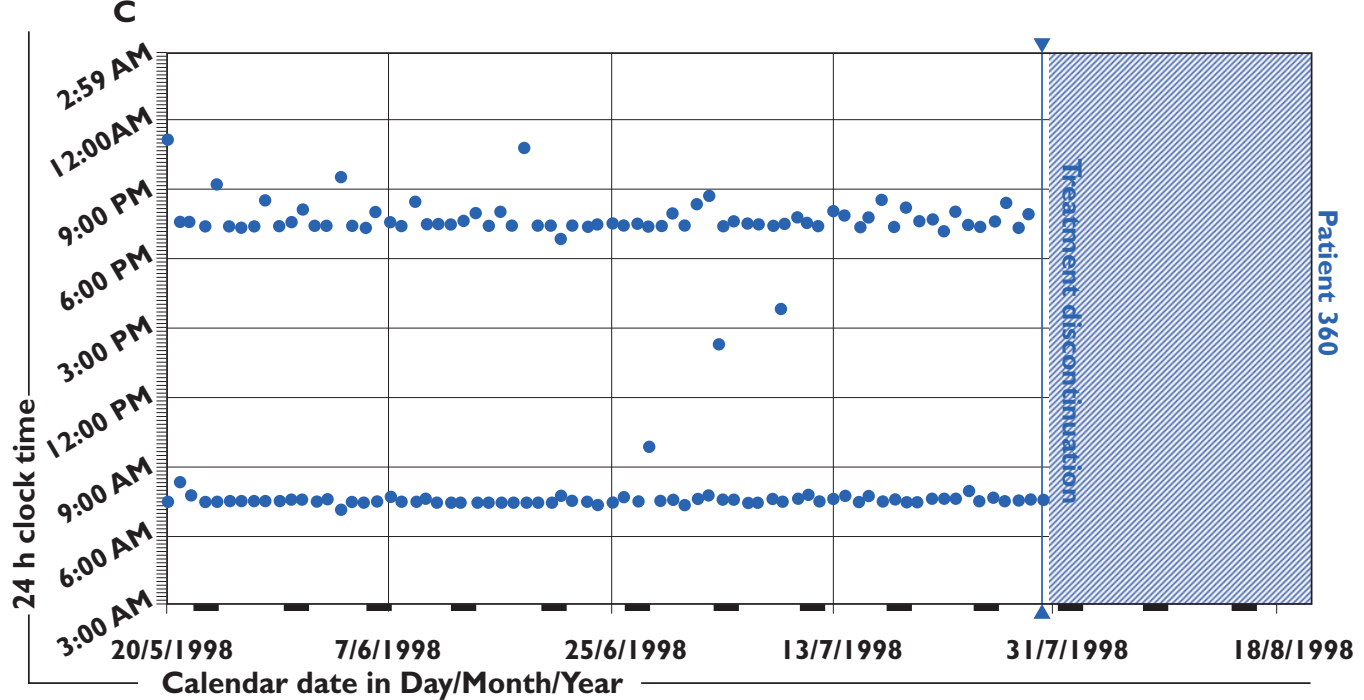

\section{Figure 5}

Examples of electronically compiled drug dosing history data in three patients for whom a twice daily dosing regimen was prescribed. Blue dots indicate the dates and times of drug intake. Grey bars indicate missed doses. (A) Patient with late initiation but good implementation. (B) Patient with suboptimal implementation (missed single and consecutive doses, large variability in timing of drug intakes). (C) Patient with excellent implementation but short persistence (early discontinuation) 
embedded in these different disciplines, making the logical or conceptual relations between them problematic [137]. The conceptual definitions for terms vary, and partly overlap, resulting in conceptual confusion, which adds to methodological weakness in the field. This problem is further compounded by a lack of congruence between conceptual definitions, operational definitions and measurements [20, 138-142].

Because of the breadth of the topic, the multiplicity of behaviours it subsumes and their various physical dimensions, one cannot use a single term and definition to meet all needs of the field. There is, however, a clear need to create a set of rules, agreed upon, within which future activities should fit, if all are committed to fulfilment of the need for clear, concise and adequate definitions and an associated conceptual framework, within which work can continue. New methods and new research findings may later force a fine tuning or even a reshaping of the field's taxonomy. Careful attention to the metrics for, and physical dimensions of, proposed terms or parameters is one of the pillars on which a sound taxonomy should rest.

Previous initiatives to standardize the taxonomy of adherence to medications were identified through the literature review. The most recent one is the attempt by the International Society for Pharmacoeconomics and Outcomes Research, but their definitions were driven by a measurement method led by refill data, which delivers only a sparse view of adherence. Our approach has integrated findings from different initiatives while remaining independent of any measurement method.

In the literature review, we have identified more than 10 different terms closely linked to the topic at hand. The proposed taxonomy is not intended to replace all of those terms, but each should find a place in the new taxonomic approach. For example, 'concordance' and 'therapeutic alliance' are elements of the management of the adherence process while 'pharmionics' is an adherence related science. The main remaining controversy is between the first term introduced, 'patient compliance' and the increasingly used one 'medication adherence'. In our view, patient compliance is synonymous with medication adherence. However, given the widely perceived, negative connotation of '(non-) compliance', and its multiple uses (e.g.compliance with drug regulations, compliance with good clinical practice, compliance with good manufacturing practice, etc.) in many different medical and peri-medical contexts, its use should fade out over time.

The main limitation of this work is associated with the development of the taxonomy based on English language literature only. This problem has been identified very early on in the process towards a unified taxonomy. During the European consensus meetings, issues regarding translation into German, French, Polish and Dutch have been discussed. Translation remains an important step for medical practice and teaching in the different countries. It is however important to have a set-up a sound taxonomy in the English language and translation will be the topic of further work in this field.

In response to the proliferation of sometimes ambiguous terms in the literature on adherence to medications, this research has resulted in a new conceptual foundation, in which we have proposed a transparent taxonomy. It should provide researchers and clinicians with a common language for describing different experimental investigations. We hope that the proffered taxonomy will stimulate discussion, informed by shared concepts, methods and research findings. The terms and definitions are focused on promoting consistency in taxonomy and methods, to aid in the conduct, analysis and interpretation of scientific studies of adherence to medications. The adoption of these terms and definitions will also help to standardize the medical literature and therefore facilitate health policy decisions based on consistent evidence.

\section{Competing Interests}

BV, JD, JU are employees of AARDEX Group SA, Sion, Switzerland. $J U$ is a minority shareholder of AARDEX Group SA. SDG is a shareholder of Therasolve NV, Diepenbeek, Belgium.

The research leading to these results has received funding from the European Union's Seventh Framework Programme FP7/2007-2013 under grant agreement $n^{\circ} 223477$.

We should like to thank Robert Vander Stichele (University of Ghent, Belgium), Lars Osterberg (Stanford University School of Medicine, Stanford, California, USA) and Patrice Chalon (Belgian Health Care Knowledge Centre, Belgium) for sharing their experience with literature reviews and their help in defining the search strategies.

\section{Appendix 1}

\section{Specific search combinations used \\ in each database \\ 1 MEDLINE via Pubmed}

('Patient compliance' [Majr] OR 'Treatment Refusal' [Majr]) AND ('Classification '[Subheading] OR 'Terminology as Topic' [MeSH] OR 'Concept Formation' [MeSH] OR 'Vocabulary, Controlled' [MeSH] OR 'primary adherence' [All Fields] OR 'primary non-adherence' [All Fields] OR 'readiness' [All Fields] OR 'pharmionics' [All Fields] OR 'treatment acceptance' [All Fields] OR 'concordance' [All Fields] OR 'definition' [All Fields] OR 'taxonomy' [All Fields] OR 'terminology' [All Fields] OR 'persistence' [All Fields] OR 'medication possession ratio' [All Fields] OR 'meta-analysis' [All Fields])

\section{EMBASE}

('Patient compliance/exp/mj) AND ('Primary compliance OR 'Primary non-compliance' OR 'Readiness' OR 'Pharmionics' OR 'Treatment acceptance' OR 'Concordance' OR 
'Persistence' OR 'Meta-analysis'/exp OR 'Definition' OR 'Taxonomy'/exp OR 'Terminology'/exp OR 'Concept') AND [EMBASE]/lim

\section{CINAHL}

('Adherence' OR 'Compliance' OR 'Persistence' OR 'Concordance' OR 'Nonadherence' OR 'Non-adherence' OR 'Noncompliance' OR 'Non-compliance') AND ('Terminology' OR 'Classification' OR 'Taxonomy' OR 'Definition')

4 The Cochrane Library

('Patient compliance' [MeSH term] AND ['Primary compliance' [topic] OR'Primary non-compliance' [topic] OR'Readiness' [topic] OR 'Pharmionics' [topic] OR 'Treatment acceptance' [topic] OR 'Meta-analysis' [topic] OR 'Concordance' [topic] OR 'Definition' [topic] OR 'Taxonomy' [topic] OR 'Concept' [topic] OR 'Persistence' [topic] OR 'Medication possession ratio' [topic])

5 PsycINFO

('Compliance' OR 'Adherence' OR 'Concordance' OR 'Persistence' OR 'Noncompliance' OR 'Non-Compliance' OR 'Nonadherence' OR 'Non-adherence') AND ('Classification' OR 'Taxonomy' OR 'Definition' OR 'Terminology')

\section{REFERENCES}

1 Osterberg L, Blaschke T. Adherence to medication. N Engl J Med 2005; 353: 487-97.

2 Rand CS. Measuring adherence with therapy for chronic diseases: implications for the treatment of heterozygous familial hypercholesterolemia. Am J Cardiol 1993; 72: 68D-74D.

3 World Health Organization. Adherence to Long-Term Therapies: Evidence for Action. Geneva: WHO, 2003.

4 Ruddy K, Mayer E, Partridge A. Patient adherence and persistence with oral anticancer treatment. CA Cancer J Clin 2009; 59: 56-66.

5 Wu JR, Moser DK, Lennie TA, Burkhart PV. Medication adherence in patients who have heart failure: a review of the literature. Nurs Clin North Am 2008; 43: 133-53.

6 Horne R. Compliance, adherence, and concordance: implications for asthma treatment. Chest 2006; 130: (1 Suppl.): 65S-72S.

7 Rapoff MA. Management of adherence and chronic rheumatic disease in children and adolescents. Best Pract Res Clin Rheumatol 2006; 20: 301-14.

8 van der Wal $\mathrm{MH}$, Jaarsma T. Adherence in heart failure in the elderly: problem and possible solutions. Int J Cardiol 2008; 125: 203-8.

9 Loghman-Adham M. Medication noncompliance in patients with chronic disease: issues in dialysis and renal transplantation. Am J Manag Care 2003; 9: 155-71.

10 Schwartz GF, Quigley HA. Adherence and persistence with glaucoma therapy. Surv Ophthalmol 2008; 53 (Suppl. 1): S57-68.
11 Schwartz GF. Compliance and persistency in glaucoma follow-up treatment. Curr Opin Ophthalmol 2005; 16: 114-21.

12 Cramer JA, Benedict A, Muszbek N, Keskinaslan A, Khan ZM. The significance of compliance and persistence in the treatment of diabetes, hypertension and dyslipidaemia: a review. Int J Clin Pract 2008; 62: 76-87.

13 Vrijens B, Urquhart J. Patient adherence to prescribed antimicrobial drug dosing regimens. J Antimicrob Chemother 2005; 55: 616-27.

14 McLean W. Medication adherence initiatives - Part I. Can Pharm J 2007; 140: 254-61.

15 Peterson AM, Takiya L, Finley R. Meta-analysis of trials of interventions to improve medication adherence. Am J Health Syst Pharm 2003; 60: 657-65.

16 Apt L, Barrett AB. Patient compliance vs. cooperation. Arch Ophthalmol 1987; 105: 315.

17 Lehane E, McCarthy G. Medication non-adherence exploring the conceptual mire. Int J Nurs Pract 2009; 15: 25-31.

18 Romano PE. Romano semantics: compliance is a better term than cooperation. Arch Ophthalmol 1988; 106: 450.

19 Romano PE. Semantics: compliance is better term than cooperation. Arch Ophthalmol 1987; 105: 314-5.

20 Andrade SE, Kahler KH, Frech F, Chan KA. Methods for evaluation of medication adherence and persistence using automated databases. Pharmacoepidemiol Drug Saf 2006; 15: 565-74.

21 Bissonnette JM. Adherence: a concept analysis. J Adv Nurs 2008; 63: 634-43.

22 Dodds F, Rebair-Brown A, Parsons S. A systematic review of randomized controlled trials that attempt to identify interventions that improve patient compliance with prescribed antipsychotic medication. Clin Effect Nurs 2000; 4: 47-53.

23 Friberg F, Scherman MH. Can a teaching and learning perspective deepen understanding of the concept of compliance? A theoretical discussion. Scand J Caring Sci 2005; 19: 274-9.

24 German PS. Compliance and chronic disease. Hypertension 1988; 11 (3 Pt 2): II56-60.

25 Gold DT. Medication adherence: a challenge for patients with postmenopausal osteoporosis and other chronic illnesses. J Manag Care Pharm 2006; 12 (6 Suppl. A): S20-5.

26 Hearnshaw $\mathrm{H}$, Lindenmeyer A. What do we mean by adherence to treatment and advice for living with diabetes? A review of the literature on definitions and measurements. Diabet Med 2006; 23: 720-8.

27 Hodari KT, Nanton JR, Carroll CL, Feldman SR, Balkrishnan R. Adherence in dermatology: a review of the last 20 years. J Dermatolog Treat 2006; 17: 136-42.

28 Karoly P. Enlarging the scope of the compliance construct: toward developmental and motivational relevance. In: 
Developmental Aspects of Health Compliance Behavior, eds Kranegor NA, Epstein LH, Johnson SB, Yaffe SJ, Hillsdale NJ: Lawrance Erlbaum Associates, Inc., 1993; 11-27.

29 Kettler LJ, Sawyer SM, Winefield HR, Greville HW. Determinants of adherence in adults with cystic fibrosis. Thorax 2002; 57: 459-64.

30 Krueger KP, Berger BA, Felkey B. Medication adherence and persistence: a comprehensive review. Adv Ther 2005; 22: 313-56.

31 Kunze M. Psychological background of noncompliance in old age. Gerontology 1982; 28 (Suppl. 1): 116-22.

32 La Greca A, Schuman WB. Adherence to prescribed medical regimens. In: Handbook of Pediatric Psychology, 2nd edn, ed. Roberts MC. New York: Guilford Press, 1995; 55-83.

33 Lahdenperä T, Kyngäs H. Compliance and its evaluation in patients with hypertension. J Clin Nurs 2000; 9: 826-33.

34 Linden M. Definition of compliance. Int J Clin Pharmacol Ther Toxicol 1981; 19: 86-90.

35 Snowden A. Medication management in older adults: a critique of concordance. Br J Nurs 2008; 17: 114-9.

36 Velligan DI, Lam YW, Glahn DC, Barrett JA, Maples NJ, Ereshefsky L, Miller AL. Defining and assessing adherence to oral antipsychotics: a review of the literature. Schizophr Bull 2006; 32: 724-42.

37 Wride N, Finch T, Rapley T, Moreira T, May C, Fraser S. What's in a name? Medication terms: what they mean and when to use them. Br J Ophthalmol 2007; 91: 1422-4.

38 NICE clinical guidelines. Available at http://www.nice.org. uk/Guidance/CG76\#documents (last accessed 13 February 2009).

39 Sawyer SM, Aroni RA. Sticky issue of adherence. J Paediatr Child Health 2003; 39: 2-5.

40 Tsoneva J, Shaw J. Understanding patients' beliefs and goals in medicine-taking. Prof Nurse 2004; 19: 466-8.

41 Hughes CM. Medication non-adherence in the elderly: how big is the problem? Drugs Aging 2004; 21: 793-811.

42 Johnson SB, Carlson DN. Medical regimen adherence: concepts, assessments, and interventions. In: Handbook of Clinical Health Psychology, Vol 2. Disorders of Behavior and Health, ed. Racsynski JM. Washington, DC: American Psychological Association, 2002; 329-54.

43 Katz Y, Goldberg M. Non-adherence, non-compliance or non-concordance in asthma: patients not following the medical regimen. Isr Med Assoc J 2007; 9: 389-90.

44 Keeling A, Utz SW, Shuster GF III, Boyle A. Noncompliance revisited: a disciplinary perspective of a nursing diagnosis. Nurs Diagn 1993; 4: 91-8.

45 Whitley GG. Noncompliance: an update. Issues Ment Health Nurs 1991; 12: 229-38.

46 Aronson JK. Time to abandon the term 'Patient concordance. Br J Clin Pharmacol 2007; 64: 711-13.

47 Barber N. Should we consider non-compliance a medical error? Qual Saf Health Care 2002; 11:81-4.
48 Bell JS, Airaksinen MS, Lyles A, Chen TF, Aslani P. Concordance is not synonymous with compliance or adherence. Br J Clin Pharmacol 2007; 64: 710-1.

49 de Almeida Neto AC, Aslani P. Medicines concordance in clinical practice. Br J Clin Pharmacol 2008; 66: 453-4.

50 Haynes RB, McDonald H, Garg AX, Montague P. Interventions for helping patients to follow prescriptions for medications. Cochrane Database Syst Rev 2002; (2): CD000011.

51 Haynes RB, Ackloo E, Sahota N, McDonald HP, Yao X. Interventions for enhancing medication adherence. Cochrane Database Syst Rev 2008; (2): CD000011.

52 Horne R, Weinman J, Barber N, Elliott R, Morgan M. Concordance, adherence and compliance in medicine taking. 2005. Report for the National Co-ordinating Centre for NHS Service Delivery and Organisation R\&D.

53 Metcalfe R. Compliance, adherence, concordance- What's in the NAME? Practical Neurology 2005; 5: 192-3.

54 Rossi S. Compliance or concordance? Australian Prescriber 2000; 23: 105.

55 Stevenson FA. Concordance: what is the relevance for pharmacists? Int J Pharm Pract 2001; 9: 67-70.

56 Treharne GJ, Lyons AC, Hale ED, Douglas KM, Kitas GD. 'Compliance' is futile but is 'concordance' between rheumatology patients and health professionals attainable? Rheumatology (Oxford) 2006; 45: 1-5.

57 Vermeire E, Hearnshaw H, Van RP, Denekens J. Patient adherence to treatment: three decades of research. A comprehensive review. J Clin Pharm Ther 2001; 26: 331-42.

58 Pitkin J. Compliance with estrogen replacement therapy: current issues. Climacteric 2002; 5 (Suppl. 2): 12-9.

59 Cals JW. Comment on: the higher the number of daily doses of antibiotic treatment in lower respiratory tract infection the worse the compliance. J Antimicrob Chemother 2009; 63: 1083-4.

60 Steiner JF, Earnest MA. The language of medication-taking. Ann Intern Med 2000; 132: 926-30.

61 Lerner BH. From careless consumptives to recalcitrant patients: the historical construction of noncompliance. Soc Sci Med 1997; 45: 1423-31.

62 Trostle JA. Medical compliance as an ideology. Soc Sci Med 1988; 27: 1299-308.

63 Vermeire E, Wens J, Van RP, Biot Y, Hearnshaw $\mathrm{H}$, Lindenmeyer A. Interventions for improving adherence to treatment recommendations in people with type 2 diabetes mellitus. Cochrane Database Syst Rev 2005; (2): CD003638.

64 Sackett DL, Haynes RB. Compliance with Therapeutic Regimens. Baltimore, MD: The Johns Hopkins University Press, 1976.

65 Moulding T. Preliminary study of the pill calendar as a method of improving the self-administration of drugs. Am Rev Respir Dis 1961; 84: 284-7. 
66 Blackwell B. Compliance. Psychother Psychosom 1992; 58: 161-9.

67 Blackwell B. Compliance. In: Handbook of Psychosomatic Medicine. 1st edn., eds Fava GA, Freyberger H. Madison, CT: International Universities Press, 1998; 625-38.

68 Lee IA, Maibach HI. Pharmionics in dermatology: a review of topical medication adherence. Am J Clin Dermatol 2006; 7: 231-6.

69 Urquhart J. Pharmionics: research on what patients do with prescription drugs. Pharmacoepidemiol Drug Saf 2004; 13: 587-90.

70 Urquhart J, Vrijens B. New findings about patient adherence to prescribed drug dosing regimens: an introduction to pharmionics. Eur J Hosp Pharm Sci 2005; 11: 103-6.

71 Blackwell B. From compliance to alliance. A quarter century of research. Neth J Med 1996; 48: 140-9.

72 Hess LM. Terminology used in medication adherence research must reflect current models of health care. Value Health 2009; 12: 630.

73 Lask B. Compliance, adherence, concordance. Br J Psychiatry 1998; 173: 271-2.

74 Myers LB, Midence K. Concepts and issues in adherence. In: Adherence to Treatment in Medical Conditions, eds Myers LB, Midence K. Amsterdam: Harwood Academic Publishers, 1998; 1-24.

75 O'Brien MK, Petrie K, Raeburn J. Adherence to medication regimens: updating a complex medical issue. Med Care Rev 1992; 49: 435-54.

76 Price PE, ed. Education, psychology and 'compliance'. Diabetes Metab Res Rev 2008; 24 (Suppl. 1): S101-5.

77 Tilson HH. Adherence or compliance? Changes in terminology. Ann Pharmacother 2004; 38: 161-2.

78 Ward-Collins D. 'Noncompliant.' Isn't there a better way to say it? Am J Nurs 1998; 98: 26-31.

79 Bernardini J. Ethical issues of compliance/adherence in the treatment of hypertension. Adv Chronic Kidney Dis 2004; 11:222-7.

80 Levensky ER. Nonadherence to treatment. In: Practioner's Guide to Evidence-Based Psychotherapy, ed. Fisher JE. New York: Springer Science + Business Media, 2006; 442-52.

81 Lutfey KE, Wishner WJ. Beyond 'compliance' is 'adherence'. Improving the prospect of diabetes care. Diabetes Care 1999; 22: 635-9.

82 Brockie J. Compliance or concordance? J Br Menopause Soc 2000; 6: 23-6.

83 Royal Pharmaceutical Society of Great Britain. From Compliance to Concordance: Towards Shared Goals in Medicine Taking. London: RPS, 1997.

84 Bokhour BG, Cohn ES, Cortes DE, Yinusa-Nyahkoon LS, Hook JM, Smith LA, Rand CS, Lieu TA. Patterns of concordance and non-concordance with clinician recommendations and parents' explanatory models in children with asthma. Patient Educ Couns 2008; 70: 376-85.

85 Chatterjee JS. From compliance to concordance in diabetes. J Med Ethics 2006; 32: 507-10.

86 Dickinson D, Wilkie P, Harris M. Taking medicines: concordance is not compliance. BMJ 1999; 319: 787.

87 Mandal A. The concept of concordance and its relation to leg ulcer management. J Wound Care 2006; 15: 339-41.

88 Marinker M. The current status of compliance. Eur Respir Rev 1998; 8: 235-38.

89 Mullen PD. Compliance becomes concordance. BMJ 1997; 314:691-2.

90 Rier DA, Indyk D. Flexible rigidity: supporting HIV treatment adherence in a rapidly-changing treatment environment. Soc Work Health Care 2006; 42: 133-50.

91 Segal JZ. 'Compliance' to 'concordance': a critical view. J Med Humanit 2007; 28: 81-96.

92 Miller NH, Hill M, Kottke T, Ockene IS. The multilevel compliance challenge: recommendations for a call to action. A statement for healthcare professionals. Circulation 1997; 95: 1085-90.

93 Elliott R. Non-adherence to medicines: not solved but solvable. J Health Serv Res Policy 2009; 14: 58-61.

94 Elliott RA, Shinogle JA, Peele P, Bhosle M, Hughes DA. Understanding medication compliance and persistence from an economics perspective. Value Health 2008; 11 : 600-10.

95 Lehane E, McCarthy G. Intentional and unintentional medication non-adherence: a comprehensive framework for clinical research and practice? A discussion paper. Int J Nurs Stud 2007; 44: 1468-77.

96 Mitchell AJ. Adherence behaviour with psychotropic medication is a form of self-medication. Med Hypotheses 2007; 68: 12-21.

97 Nordqvist O, Sodergard B, Tully MP, Sonnerborg A, Lindblad AK. Assessing and achieving readiness to initiate HIV medication. Patient Educ Couns 2006; 62: 21-30.

98 Shearer HM, Evans DR. Adherence to health care. In: Handbook of Cultural Health Psychology, eds Kazarian SS, Evans DR. San Diego, CA: US Academic Press, 2001; 113-38.

99 Stevenson FA. Concordance. Soc Theory Health 2004; 2: 184-93.

100 Chisholm-Burns MA, Spivey CA. Pharmacoadherence: a new term for a significant problem. Am J Health Syst Pharm 2008; 65: 661-7.

101 Kampman O, Lehtinen K. Compliance in psychoses. Acta Psychiatr Scand 1999; 100: 167-75.

102 Kyngas H, Duffy ME, Kroll T. Conceptual analysis of compliance. J Clin Nurs 2000; 9: 5-12.

103 Leventhal H, Lambert JF, Diefenbach M, Leventhal EA. From compliance to social-self-regulation: models of the compliance process. In: Treatment Compliance and the 
Therapeutic Alliance, ed. Blackwell B. Amsterdam: Harwood Academic Publishers, 1997; 17-33.

104 Madden BP. The hybrid model for concept development: its value for the study of therapeutic alliance. ANS Adv Nurs Sci 1990; 12: 75-87.

105 Weiden PJ, Rao N. Teaching medication compliance to psychiatric residents: placing an orphan topic into a training curriculum. Acad Psychiatry 2005; 29: 203-10.

106 Bond C. Concordance- Is it a synonym for compliance or a paradigm shift? Pharm J 2003; 271:496-7.

107 Gray R, Wykes T, Gournay K. From compliance to concordance: a review of the literature on interventions to enhance compliance with antipsychotic medication. J Psychiatr Ment Health Nurs 2002; 9: 277-84.

108 Hobden A. Concordance: a widely used term, but what does it mean? Br J Community Nurs 2006; 11:257-60.

109 Feinstein AR. On white-coat effects and the electronic monitoring of compliance. Arch Intern Med 1990; 150: 1377-8.

110 La Greca AM. Issues in adherence with pediatric regimens. J Pediatr Psychol 1990; 15: 423-36.

111 Fincham JE, Wertheimer Al. Using the health belief model to predict initial drug therapy defaulting. Soc Sci Med 1985; 20: 101-5.

112 Aronson JK. Compliance, concordance, adherence. Br J Clin Pharmacol 2007; 63: 383-4.

113 Donovan JL, Blake DR. Patient non-compliance: deviance or reasoned decision-making? Soc Sci Med 1992; 34: 507-13.

114 Kontz MM. Compliance redefined and implications for home care. Holist Nurs Pract 1989; 3: 54-64.

115 Anthonisen NR. Persistence and compliance. Can Respir J 2004; 11: 13-4.

116 Burnier M. Medication adherence and persistence as the cornerstone of effective antihypertensive therapy. Am J Hypertens 2006; 19: 1190-6.

117 Chen $\mathrm{CH}$, Wu JR, Yen M, Chen ZC. A model of medication-taking behavior in elderly individuals with chronic disease. J Cardiovasc Nurs 2007; 22: 359-65.

118 Colom F, Vieta E, Tacchi MJ, Sanchez-Moreno J, Scott J. Identifying and improving non-adherence in bipolar disorders. Bipolar Disord 2005; 7 (Suppl. 5): 24-31.

119 Cramer JA, Roy A, Burrell A, Fairchild CJ, Fuldeore MJ, Ollendorf DA, Wong PK. Medication compliance and persistence: terminology and definitions. Value Health 2008; 11:44-7.

120 Ekedahl A, Oskarsson V, Sundberg B, Gustafsson V, Lundberg T, Gullberg B. Impact of postal and telephone reminders on pick-up rates of unclaimed e-prescriptions. Pharm World Sci 2008; 30: 503-8.

121 Hudson M, Rahme E, Richard H, Pilote L. Comparison of measures of medication persistency using a prescription drug database. Am Heart J 2007; 153: 59-65.
122 Hughes D, Cowell W, Koncz T, Cramer J. Methods for integrating medication compliance and persistence in pharmacoeconomic evaluations. Value Health 2007; 10 : 498-509.

123 Lafleur J, Oderda GM. Methods to measure patient compliance with medication regimens. J Pain Palliat Care Pharmacother 2004; 18: 81-7.

124 Lopatriello S, Berto P, Cramer J, Bustacchini S, Ruffo P. Different aspects of adherence to antihypertensive treatments. Expert Rev Pharmacoecon Outcomes Res 2004; 4: 317-33.

125 Rachid A. Do patients cash prescriptions? Br Med J (Clin Res Ed) 1982; 284: 24-6.

126 Sodergard B, Hofer S, Halvarsson M, Sonnerborg A, Tully MP, Lindblad AK. A structural equation modeling approach to the concepts of adherence and readiness in antiretroviral treatment. Patient Educ Couns 2007; 67: 108-16.

127 Strom O, Borgstrom F, Kanis JA, Jonsson B. Incorporating adherence into health economic modelling of osteoporosis. Osteoporos Int 2009; 20: 23-34.

128 Urquhart J, Vrijens B. Taxonomy of patient compliance-related events in drug trials. Snowbird conference on causal inference 2001. 2001.

129 Kemppainen JK, Levine R, Buffum M, Holzemer W, Finley P, Jensen $P$. Antiretroviral adherence in persons with HIV/AIDS and severe mental illness. J Nerv Ment Dis 2004; 192: 395-404.

130 Kothawala P, Badamgarav E, Ryu S, Miller RM, Halbert RJ. Systematic review and meta-analysis of real-world adherence to drug therapy for osteoporosis. Mayo Clin Proc 2007; 82: 1493-501.

131 Dunbar J. Adherence measures and their utility. Control Clin Trials 1984; 5: (4 Suppl.): 515-21.

132 Vrijens B, Vincze G, Kristanto P, Urquhart J, Burnier M. Adherence to prescribed antihypertensive drug treatments: longitudinal study of electronically compiled dosing histories. BMJ 2008; 336: 1114-7.

133 Fine RN, Becker $Y$, De GS, Eisen H, Ettenger R, Evans R, Rudow DL, McKey D, Neu A, Nevins T, Reyes J, Wray J, Dobbels F. Nonadherence consensus conference summary report. Am J Transplant 2009; 9: 35-41.

134 Urquhart J. Role of patient compliance in clinical pharmacokinetics. A review of recent research. Clin Pharmacokinet 1994; 27: 202-15.

135 Flexner C. Pharmacoecology: a new name for an old science. Clin Pharmacol Ther 2008; 83: 375-9.

136 Demyttenaere K. Compliance during treatment with antidepressants. J Affect Disord 1997; 43:27-39.

137 Evangelista LS. Compliance: a concept analysis. Nurs Forum 1999; 34: 5-11.

138 Caetano PA, Lam JM, Morgan SG. Toward a standard definition and measurement of persistence with drug therapy: 
examples from research on statin and antihypertensive utilization. Clin Ther 2006; 28: 1411-24.

139 Cleemput I, Kesteloot K, DeGeest S. A review of the literature on the economics of noncompliance. Room for methodological improvement. Health Policy 2002; 59: 65-94.

140 Halpern MT, Khan ZM, Schmier JK, Burnier M, Caro JJ, Cramer J, Daley WL, Gurwitz J, Hollenberg NK. Recommendations for evaluating compliance and persistence with hypertension therapy using retrospective data. Hypertension 2006; 47: 1039-48.

141 Peterson AM, Nau DP, Cramer JA, Benner J, Gwadry-Sridhar F, Nichol M. A checklist for medication compliance and persistence studies using retrospective databases. Value Health 2007; 10: 3-12.
142 Sikka R, Xia F, Aubert RE. Estimating medication persistency using administrative claims data. Am J Manag Care 2005; 11: 449-57.

143 Haynes RB, Taylor DW, Sackett DL. Compliance in Health Care. Baltimore, MD: Johns Hopkins University Press, 1979.

144 Dracup KA, Meleis Al. Compliance: an interactionist approach. Nurs Res 1982; 31:31-6.

145 Meichenbaum D, Turk DC. Facilitating Treatment Adherence: A Practioner's Guidebook. New York: Plenum, 1987.

146 Balkrishnan R. The importance of medication adherence in improving chronic-disease related outcomes: what we know and what we need to further know. Med Care 2005; 43: 517-20. 